\title{
Habenula and Thalamus Cell Transplants Restore Normal Sleep Behaviors Disrupted by Denervation of the Interpeduncular Nucleus
}

\author{
Forrest Haun, Theresa C. Eckenrode, and Marion Murray \\ Department of Anatomy and Neurobiology, Medical College of Pennsylvania, Philadelphia, Pennsylvania 19129
}

The preceding companion study (Eckenrode et al., 1992) showed that cell suspension transplants of fetal habenula cells placed near the interpeduncular nucleus (IPN) following lesions of the fasciculus retroflexus (FR) restore the normal pattern of substance P (SP) staining in habenular target subnuclei of the IPN in both perinatal and adult hosts, and restore ChAT staining in the IPN of perinatal hosts. Similarly placed transplants of fetal thalamus cells only restore ChAT staining in the IPN of adult hosts. In this study, we examined the functional significance of these restored staining patterns. We used a behavioral measure of the integrity of REM-stage and non-REM-stage sleep, the "flower pot" test, and assayed (1) normal adult rats, (2) FR-lesioned control animals (neonatal or adult operates), (3) animals receiving FR lesions and transplants of fetal habenula cells (perinatal or adult hosts), and (4) animals receiving FR lesions and transplants of fetal thalamus cells (adult hosts). FR lesions decrease markedly the muscle atonia component of REM sleep and reduce duration of sleep episodes. Transplants that restore SP staining in the IPN (habenular transplants into either perinatal or adult lesion hosts) restore normal frequency of REM atonia; transplants that restore ChAT staining (habenular transplants into perinatal hosts or thalamic transplants into adult hosts) restore normal duration of sleep episodes. The number of SP-immunoreactive cells in the transplants predicts recovery of REM atonia, and the number of ChAT cells in habenular (but not thalamic) transplants predicts restoration of sleep duration. We conclude that the IPN is important in the regulation of normal sleep patterns, and particularly that transmitter-specific innervation of habenular SP targets modulates the integrity of REM sleep, while transmitter-specific innervation of habenular cholinergic targets modulates sleep duration, but only when the cholinergic innervation is mediated by normal habenular afferents.

The most compelling evidence for the integration of neural transplants into the functioning of an organism is behavioral, and examples of such transplant-mediated behavioral recovery following brain damage abound (e.g., Bjorklund et al., 1980;

\footnotetext{
Received Dec. 11, 1991; revised Mar. 9, 1992; accepted Mar. 25, 1992.

This work was supported by NIH Grants NS28856 (F.H.) and NS16556 (M.M.) We are especially grateful to Jennifer McSparren Miller and Sarah Kennedy for dedicated assistance in conducting the behavioral assay, and for comments on the manuscript provided by Dr. E. Hazel Murphy.

Correspondence should be addressed to Marion Murray, Ph.D., Department of Anatomy and Neurobiology, The Medical College of Pennsylvania, 3200 Henry Avenue, Philadelphia, PA 19129.

Copyright (C) 1992 Society for Neuroscience $0270-6474 / 92 / 123282-09 \$ 05.00 / 0$
}

Freed et al., 1980; Dunnett et al., 1982, 1985, 1987; Gage and Bjorklund, 1986; Haun et al., 1989; Kunkel-Bagden and Bregman, 1990; Ralph et al., 1990). The extent of behavioral recovery has been related to the degree of host innervation by the transplant, most often by qualitative assessment (e.g., Dunnett et al., 1982, 1989; Gage and Bjorklund, 1986; Nilsson et al., 1987) but in one recent study quantitatively (Klassen and Lund, 1990). A quantitative correlation has also been shown between the number of dopamine neurons in ventral mesencephalic transplants grafted into the unilaterally denervated striatum and the extent of transplant-mediated improvement in the animals' turning behavior (Brundin et al., 1988).

We have been studying the regulation of innervation of the interpeduncular nucleus (IPN) by cell suspension transplants of habenular origin in host animals with lesions of the normal habenula input to the IPN. This input contains both cholinergic and peptidergic components, and originates in the cholinergic and peptidergic cells of the medial habenula (Artymyshyn and Murray, 1985; Contestabile et al., 1987; Eckenrode et al., 1987). In the preceding companion article (Eckenrode et al., 1992), we showed that transplant-mediated innervation was restricted to normal habenular target subnuclei in the IPN, and that the patterns of peptidergic versus cholinergic innervation were distinctly different (Eckenrode et al., 1992). In this study, we asked whether these transplants also affect the animals' behavior, and whether the degree of this cffect is predictable from the number of peptidergic or cholinergic cells in the transplants.

For the behavioral assay, we used a simple all-or-none measure of the animals' REM sleep, based on the classic platform or "flower pot" technique. In this assay, the animal is placed on a small-diameter platform in a tank of water during its normal sleep period. As the animal enters REM-stage sleep, the muscle atonia component of REM causes the animal to lose postural tone, falling toward and sometimes into the water, then quickly awakening in response to loss of balance or water contact. This results in a near-complete absence of REM-stage sleep, while non-REM components remain largely unaffected (Mendelson et al., 1974; McGrath and Cohen, 1978; Bergmann et al., 1989) This technique is often used as a reliable means of depriving rodents of REM-stage sleep chronically. We used it as an acute assay to test whether removal of habenular input to the IPN disrupts normal sleep patterns to the extent that the most extreme manifestation of REM atonia, water contact, is affected. In addition, we measured the duration of each sleep episode while the animals were on the platform during the test period. Since the REM stage accounts for only about $10 \%$ of rodents' total sleep time (e.g., Kushida et al., 1989), the total time spent in each sleep episode is primarily a measure of non- 
REM components. These are commonly used behavioral measures of rodent sleep because they are known to correlate with EEG sleep patterns (Morden et al., 1967; Swisher, 1962; Mendelson et al., 1974).

There is no evidence that either the habenula or the IPN directly controls any aspect of sleep. However, there are major efferents from the IPN to the median and dorsal raphe, and to the dorsal and dorsolateral tegmentum (Shibata and Suzuki, 1984; Groenewegen et al., 1986), areas strongly implicated in control of several components of the sleep/wake cycle (Quattrochi et al., 1989; Steriade and McCarley, 1990; Vertes, 1990). Metabolically, the normally high level of activity in the IPN is unchanged or selectively increased during sleep as well as anesthesia (Herkenham, 1981; Kennedy et al., 1982; McQueen et al., 1984); during REM sleep in particular, metabolic activity in the habenula is also increased (Lydic et al., 1991). Lesions of the fasciculus retroflexus (FR), which remove the medial habenula input to the IPN, also abolish the high level of metabolic activity in the IPN of waking animals as well as eliminate the selective sparing during anesthesia (Herkenham, 1981; Motohashi et al., 1986; Barr et al., 1987). Thus, the anatomical circuitry of the habenulo-interpeduncular system and its metabolic pattern suggest a possible involvement in the sleep/wake cycle.

\section{Materials and Methods}

\section{Surgery}

Bilateral thermal lesions of the fasciculi retroflexi (FR) were made in either 3-10-d-old or adult female Sprague-Dawley rats, using procedures described in detail in previous reports (Artymyshyn and Murray, 1985; Eckenrode et al., 1992). Ten animals with perinatal lesions and 14 animals with adult lesions received transplants of habenula cells. To control for nonspecific effects of the transplants, eight other animals with adult lesions received transplants of thalamus cells. Remaining operated animals ( 12 with perinatal lesions, 13 with adult lesions) served as lesion-only controls. In addition, 12 normal fcmalc littermates of these operates were also tested on the behavior assay (Table 1).

All animals were tested 2-3 months postlesion; adult operates were 5-6 months of age at time of testing.

\section{Transplant methods}

Procedures for harvesting and transplantation of donor tissue are described in detail in the preceding companion article (Eckenrode et al., 1992). Briefly, donor tissue was taken from Sprague-Dawley rat embryos at 14-15 days gestation after the dams had been deeply anesthetized. Embryos were extracted singly and placed on a cold pack, and then both habenulae were excised after reflection of the cortices. For the thalamus dissection, the ball-shaped diencephalon was first removed to ensure that no adjacent striatal or basal telencephalic structures were included. Then, the hypothalamus was dissected away along the hypothalamic sulcus. The remaining portion of the diencephalon was cut into quarters and the ventral posterior quadrant taken.

Prior to transplantation the tissue was "precultured" for 4-5 d in vitro, a procedure that may encourage more consistent transplant volumes and integration (Haun and Cunningham, 1987). Two picces of either habenula or posterior thalamus were co-cultured as explants in a $35 \mathrm{~mm}$ dish coated to inhibit fibroblast outgrowth, using a modified Ham's F-10 medium (Eagleson et al., 1990).

At the end of the culturing period, tissue pieces were dissociated in a trypsin cocktail, and the resulting cell suspension was assayed for viability; the amount of cell suspension transplanted was adjusted so that approximately the same number of viable cells $\left(6-8 \times 10^{4}\right)$ was placed into each host (Brundin et al., 1985).

Host animals had received the bilateral FR lesions either 3-6 d (perinatal hosts) or 7-10 d (adult hosts) prior to transplantation. Hosts were anesthetized and placed in a stereotaxic apparatus, and then a glass micropipette containing the cell suspension transplant was lowered into the midbrain using predetermined coordinates intended to deposit the
Table 1. Numbers of animals in behavior study

\begin{tabular}{lrrrl} 
& & & & $\begin{array}{l}\text { Trans- } \\
\text { Lesions } \\
\text { plants } \\
\text { seen }\end{array}$ \\
\hline Normal & Operated & Tested & complete & - \\
FR lesion only & - & 12 & - & - \\
$\quad$ P3-P10 & 12 & 9 & 7 & - \\
$\quad$ Adult & 13 & 13 & 12 & - \\
FR lesion + transplant & & & & \\
P3-P10 - habenula & 10 & 8 & 5 & 4 \\
Adult - habenula & 14 & 13 & 11 & 10 \\
Adult - thalamus & 8 & 7 & 5 & 5
\end{tabular}

Operated animals received bilateral lesions of the FR either perinatally [3-10 d of age (P3-P10)] or as adults. Transplants were of either habenular or thalamic origin. After behavior testing, brains were examined histologically for completeness of FR lesion and presence of a transplant.

transplant just rostral to the IPN. Cells were injected slowly, and then the needle was removed and the wound sutured before returning the host to its home cage.

\section{Rehavioral assay}

Behavioral testing began 2-3 months postlesion. The rat was placed on the base of an inverted flower pot $(5.5 \mathrm{~cm}$ diameter) attached to the bottom of a $30 \times 58 \mathrm{~cm}$ glass fish tank containing tap water $(\sim 20$ $22^{\circ} \mathrm{C}$ ). Water depth was $6 \mathrm{~cm}$, with the top of the flower pot extending $1 \mathrm{~cm}$ above water level. The animal was placed on the pot beginning at the same time each day (10 A.M. or 11 A.M.), with the length of time gradually increasing over the first 3 acclimation days $(0.5 \mathrm{hr}, 1 \mathrm{hr}$, and $3 \mathrm{hr}$ per day, respectively). On the fourth day, the animal was placed on the pot for $3 \mathrm{hr}$, the last hour of which was the test period.

The total number of sleep episodes and water contacts was recorded for each animal in the $1 \mathrm{hr}$ test period; the duration of each sleep episodc was also recorded, and the median time calculated for each animal. Onset of a sleep episode was considered to have occurred when either (1) the animal's eyes closed fully or (2) the eyes were partially closed and the rat had a hunched-over posture (Rideout, 1979). Cessation of a sleep episode was indicated by either eye opening or a sudden straightening of body posture, which often occurred simultaneously; posture straightening alone sometimes occurred following water contact. When water contact occurred, it was usually by the rat's snout, and was always followed immediately by cessation of the sleep episode (Fig. 1).

Weight and rectal temperature were recorded just prior to the beginning and at the end of the $4 \mathrm{~d}$ procedure. The number of grooming episodes was recorded during the test period, along with the number of fecal boli in the tank at the end of the last day's session.

Each animal was tested by one of four observers over the course of this study, all of whom were unaware of the surgical history of the tested animals. Each observer tested animals from each of the groups in the study.

\section{Anatomical methods}

Lesion verification and immunocytochemistry. At the conclusion of behavioral testing, the animals were overdosed with chloral hydrate and perfused intracardially with normal saline, followed by $4 \%$ paraformaldehyde. Brains were removed, blocked, and cut on a cryostat in 30 $\mu \mathrm{m}$ sections, and then processed for cresyl violet staining and substance $\mathrm{P}$ (SP) and ChAT immunocylochemistry as described in the preceding article (Eckenrode et al., 1992). Brains were blocked such that the FR lesion site and the transplant were in different blocks. The slides were coded so that success of the lesion was determined and morphometric analyses of transplants were performed without knowledge of the animals' behavioral performance. Lesions were judged complete by the presence of obvious degeneration in both FR tracts, which is seen in cresyl violet-stained sections as gliotic replacement of the tracts.

Morphometry. Transplant volume was calculated from planimetric. measurements of camera lucida drawings of the cresyl violet-stained sections at $120 \mu \mathrm{m}$ intervals. Transplant boundaries were usually dis- 
tinct because of their greater cell density compared to surrounding host; in cases of doubt, adjacent immunocytochemically processed sections were examined for aggregations of SP- and ChAT-positive cells, which also served to distinguish transplant from host (see Eckenrode et al., 1992).

SP-and ChAT-positive cells were counted at $90 \mu \mathrm{m}$ intervals throughout the entire extent of the transplants. Calculations of total numbers used the appropriate Abercrombie (1946) correction for differences in cell diameter ("Abercrombie II"). This method of calculating total cell number from sample sections has been used in previous studies of the number of cells of a particular neurotransmitter phenotype in transplants (e.g., Brundin et al., 1988), and has been shown to provide an accurate estimate of actual cell numbers in a structure when cell diameter is less than section thickness (Smolen et al., 1983). In this study, the largest cells (ChAT positive) had 8-15 $\mu$ m diameters, therefore never more than half the section thickness.

\section{Statistics}

For the behavioral data, statistical comparisons are with the MannWhitney $U$ test, corrected for multiple comparisons by Ryan's procedure (Kirk, 1968). For the anatomical data, comparisons are with post hoc multiple comparison $t$ tests following separate ANOVAs of the volume and cell counts data. Correlations of the behavioral and anatomical data compare linear and several polynomial regression equations (GB-STAT, version 2.0); the model yielding the highest coefficient of determination $\left(\dot{r}^{2}\right)$ is reported, provided it explains at least $10 \%$ more of the variance than the model with one less term. Mean values are expressed \pm SEM.

\section{Results}

In the 2-3 month interval between surgery and testing, four animals died (survival rate, 93\%): three perinatally lesioned animals (one with a habenula transplant) and one adult-lesioned (with a thalamus transplant). Of the remaining animals, two did not complete behavioral testing: one perinatal lesion-only and one perinatal lesion-plus-transplant animal exhibited chronic turning behavior on the platform in the first $2 \mathrm{~d}$, and further testing was discontinued. Behavioral data are reported for all other operates that subsequent histological examination showed had complete bilateral FR lesions, and for all transplant animals with a histologically detectable transplant (see Table 1 ).

Behavioral results are also included from four transplant animals that died prior to perfusion (two perinatal hosts, one adult host with habenula transplant, one adult host with thalamus transplant). Transplant volumes and cell numbers were calculated from remaining transplant animals (Table 2). SP and ChAT staining were examined in the IPN of all animals not otherwise used for other studies, and those results are included in the preceding article (Eckenrode et al., 1992).

\section{Morphometry}

The volume of habenula cell transplants in perinatal hosts is not significantly different from the volume in adult hosts, and likewise the volumes of habenula and thalamus cell transplants in adult hosts are not significantly different [ANOVA, $F(2,16)$ $=0.472, p=0.63$ ].

There are however major differences among the different types of transplants in the numbers of SP-positive and ChAT-positive cells (Table 2). In habenular transplants, SP cell number varies widely: $43-417$ in adult hosts and 88-679 in perinatal hosts; the mean values are not significantly different. However, the number of ChAT-positive cells in habenula transplants is sig-

Figure 1. Behavioral test. $A$, The rat is placed on a small-base inverted flower pot affixed to the bottom of a glass fish tank containing cold water. $B$, As the animal begins a sleep episode, it closes its eyes and
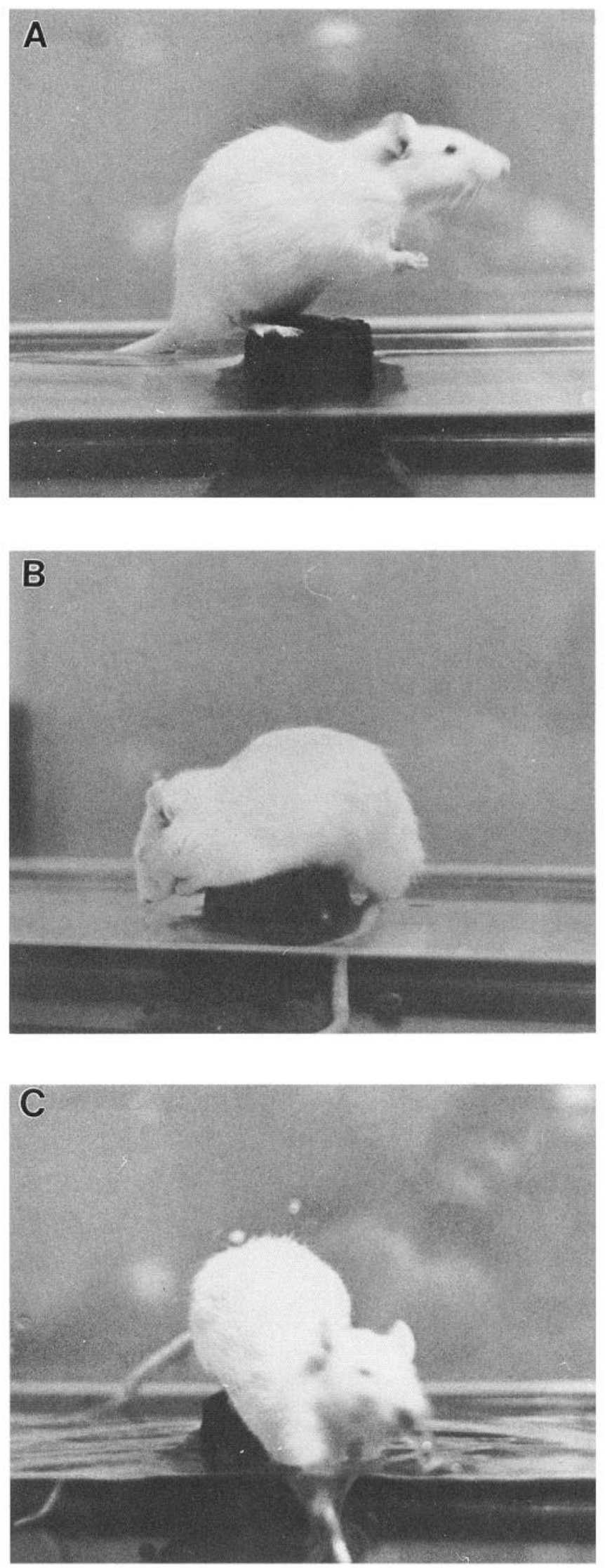

hunches over. As REM-stage sleep begins, muscle tone becomes flaccid and the animal either leans to one side before "catching" itself and resuming a more upright posture, or falls into the water $(C)$. 


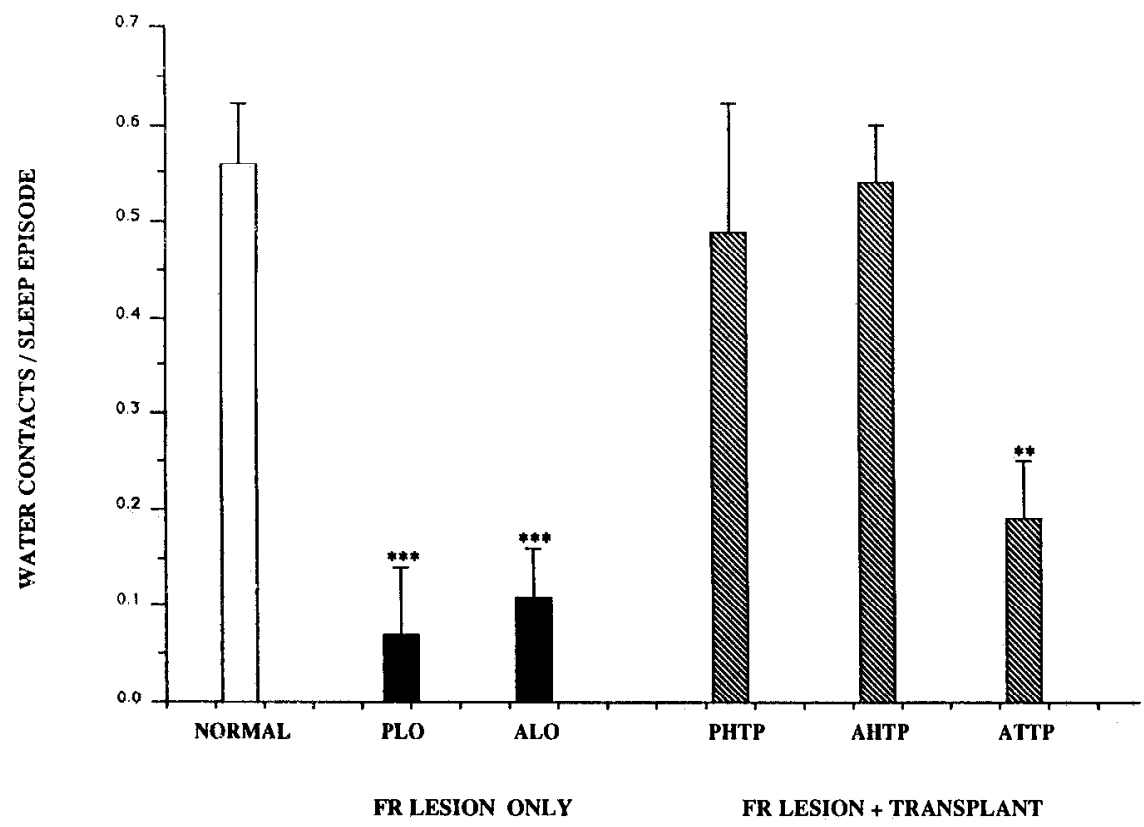

Figure 2. Water contacts during behavioral test. A significantly smaller fraction of sleep episodes end in REM atonia-induced water contact by animals with FR lesions, whether the lesion is made in perinatal animals $(P L O$ $0.07 \pm 0.07)$ or in adults $(A L O ; 0.11 \pm$ $0.05)$, compared to normals $(0.56 \pm$ 0.06). Animals with FR lesions plus transplants that mediate SP reinnervation of the IPN show normal frequencies $[0.49 \pm 0.13$ in perinatal hosts with habenular transplants (PHTP), $0.54 \pm 0.06$ in adult hosts with habenular transplants $(A H T P)]$. However, mean water contact frequency remains significantly reduced in hosts with transplants that do not support SP reinnervation $[0.19 \pm 0.06$ in adults with thalamus cell transplants $(A H T P)]$. Mcans arc \pm SEM. ${ }^{* *}, p<0.01 ;{ }^{* * *}, p$ $<0.001$ for comparisons of operated groups with normals, by corrected Mann-Whitney test. $n=12$ for normal, $n=9$ for $A L O$ and $A H T P, n=6$ for $P H T P$ and $A T T P$, and $n=5$ for PLO. Animals undergoing no sleep episodes during the test period are not included (three $A L O$, two $P L O$, and two $A H T P$ animals). nificantly less in adult hosts compared to perinatal hosts: the range in adults is $0-249$, with half containing fewer than 100 cholinergic cells, while the range in perinatal hosts is 105-567.

In thalamic transplants there are consistently small numbers of SP-positive cells, 15-112. Unexpectedly, there are many ChAT-positive cells, 185-693, a range practically identical to that found in habenula transplants of perinatal hosts. The thalamic cholinergic cells are particularly large and well differentiated (Eckenrode et al., 1992). In adult-lesioned hosts, therefore, transplants of thalamic origin contain significantly greater numbers of ChAT-positive cells than do transplants of habenular origin, despite the absence of cholinergic cells in the normal mature thalamus.

Table 2. Summary of transplant volumes and cell types

\begin{tabular}{lccc}
$\begin{array}{l}\text { Donor origin } \\
\text { (host age) }\end{array}$ & Volume $\left(\mathrm{mm}^{3}\right)$ & $\begin{array}{l}\text { Number of } \\
\text { SP cells }\end{array}$ & $\begin{array}{c}\text { Number of } \\
\text { ChAT cells }\end{array}$ \\
\hline $\begin{array}{c}\text { Habenula } \\
\text { (P3-P10) } \\
n=4\end{array}$ & $\begin{array}{c}0.266 \\
( \pm 0.114)\end{array}$ & $\begin{array}{c}316 \\
( \pm 113)\end{array}$ & $\begin{array}{c}393 \\
( \pm 89)\end{array}$ \\
$\begin{array}{c}\text { Habenula } \\
\text { (adult) }\end{array}$ & 0.168 & 176 & $94^{* *}$ \\
$n=10$ & $( \pm 0.056)$ & $( \pm 33)$ & $( \pm 24)$ \\
$\begin{array}{c}\text { Thalamus } \\
\text { (adult) } \\
n=5\end{array}$ & 0.265 & $50^{*}$ & 388 \\
& $( \pm 0.139)$ & $( \pm 20)$ & $( \pm 121)$
\end{tabular}

Values are means \pm SEM. The significant differences are between (1) number of ChAT cells in habenula transplants (adult hosts) and ChAT cell number in either habenular transplants (perinatal hosts) or thalamus transplants, ${ }^{* *}=p<0.01$; and (2) number of SP cells in thalamus transplants and either SP cell number in habenula transplants (perinatal hosts) or ChAT cell number in thalamus transplants, ${ }^{*}=p<0.05$. SP cell number in thalamus transplants (adult hosts) just misses being significantly less than SP cell number in habenula transplants (adult hosts), $p<0.07$.

\section{Sleep behaviors}

Sleep episodes. Animals receiving bilateral lesions of the FR as adults experience half the number of sleep episodes during the $1 \mathrm{hr}$ test period as do normal animals: $6.9( \pm 2.0)$ sleep episodes for the adult FR-lesion group compared to $15.6( \pm 2.0)$ for normals $(p<0.01)$. In contrast, animals receiving bilateral FR lesions perinatally have $8.7( \pm 4.1)$ sleep episodes, which is not significantly different from normal. In three of these six perinatal FR-lesion animals, the number of sleep episodes is within $1 \mathrm{SD}$ of normal.

Transplants of either habenula or thalamus cells restore normal frequency of sleep episodes: $12.0( \pm 2.4)$ episodes per hour in adult hosts with habenula transplants, and $11.0( \pm 3.4)$ per hour in adult hosts with thalamus transplants, both of which are not significantly different from normal. A normal frequency of sleep episodes is also seen in perinatally lesioned animals with habenula transplants, $12.0( \pm 2.9)$ per hour.

Water contacts (Fig. 2). The number of water contacts during the test period, expressed per sleep episode, is also severely reduced following bilateral FR lesions, whether the lesions are made perinatally or as adults. In fact, most lesion-only animals fail to contact the water in any sleep episode.

Transplants of habenular cells into either perinatal- or adultlesioned hosts result in normal water contact frequency, whereas thalamus cell transplants are ineffective in ameliorating any part of this deficit.

Sleep episode duration (Fig. 3). The disruption of the lesiononly animals' sleep pattern is further evident in the significantly reduced time these animals spend in each sleep episode. Transplants of habenula cells do not improve this aspect of the lesioninduced sleep disruption, when placed into adult hosts, but when placed into perinatal hosts, habenula cell transplants restore sleep duration to normal levels. In contrast to water contact frequency, sleep duration is improved by transplants of thalamus cells into adult hosts. 
Figure 3. Sleep episode duration during behavioral test. FR lesions result in significantly shorter duration of sleep episodes $(29 \pm 8 \mathrm{sec}$ in the $P L O$ group $34 \pm 5 \mathrm{sec}$ in the $A L O$ group; see Fig. 2 for abbreviations and $n$ values), compared to normal $(65 \pm 11 \mathrm{sec})$. Animals with lesions plus transplants that mediate cholinergic reinnervation of the IPN have sleep episode times that are similar to normals $(61 \pm 11 \mathrm{sec}$ in the PHTP group, $56 \pm 13 \mathrm{sec}$ in the $A T T P$ group). Duration remains significantly less than normal for animals with transplants that do not support cholinergic reinnervation $(33 \pm 5 \mathrm{sec}$ in the $A H T P$ group). ${ }^{*}, p<0.05 ;{ }^{* *}, p<0.01$ for comparisons of operated groups with normals, by corrected Mann-Whitney test.

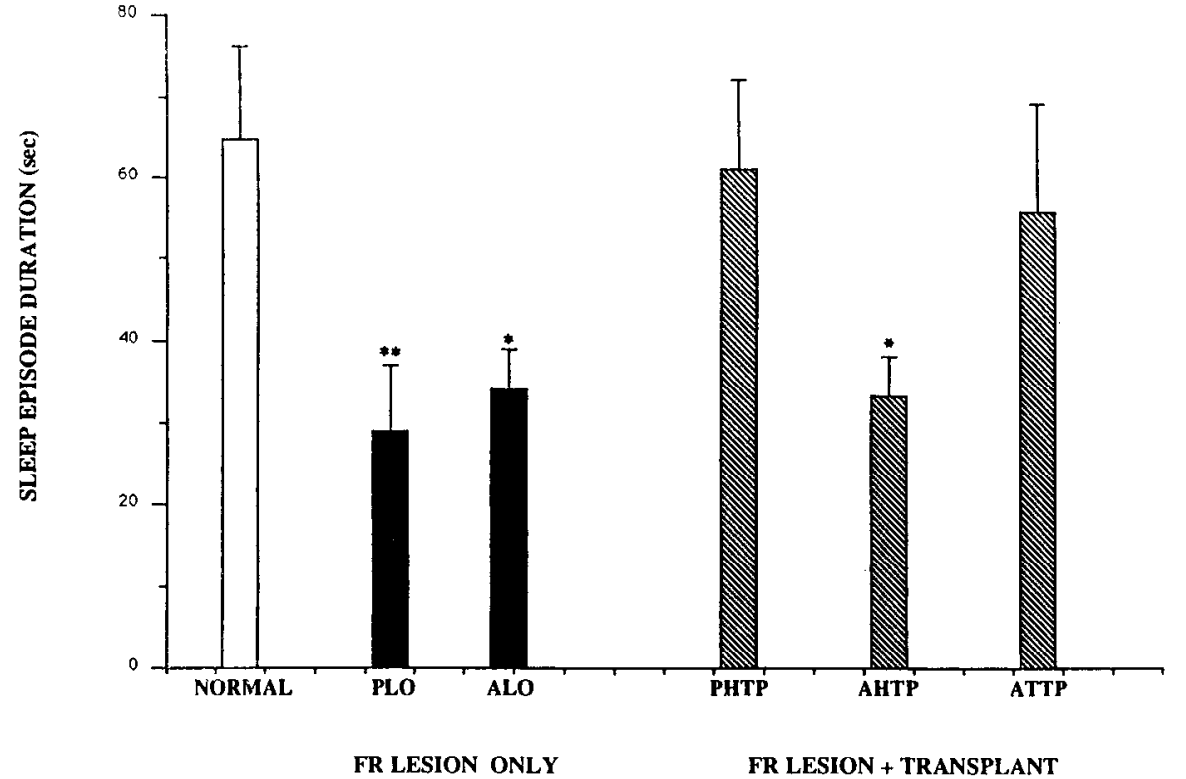

The number of ChAT cells in habenula transplants predicts improvement in the duration of sleep episodes $\left[r_{\text {lin }}=0.66, F(10)\right.$ $=7.534, p<0.02$; Fig. 5]. This correlation is significant only for animals with habenula transplants. Adding the data from animals with thalamus transplants reduces the correlation to $r_{\text {lin }}$ $=0.32$, which is not significant $(p=0.21)$. Furthermore, the significant correlation for animals receiving habenula transplants is entirely dependent on the perinatal hosts; adult hosts with habenula transplants show no significant correlation between ChAT number and sleep duration $\left(r_{\text {lin }}=0.08\right.$.) The range of ChAT cell numbers in habenula transplants is greater in perinatal compared to adult hosts (see above), so the significant

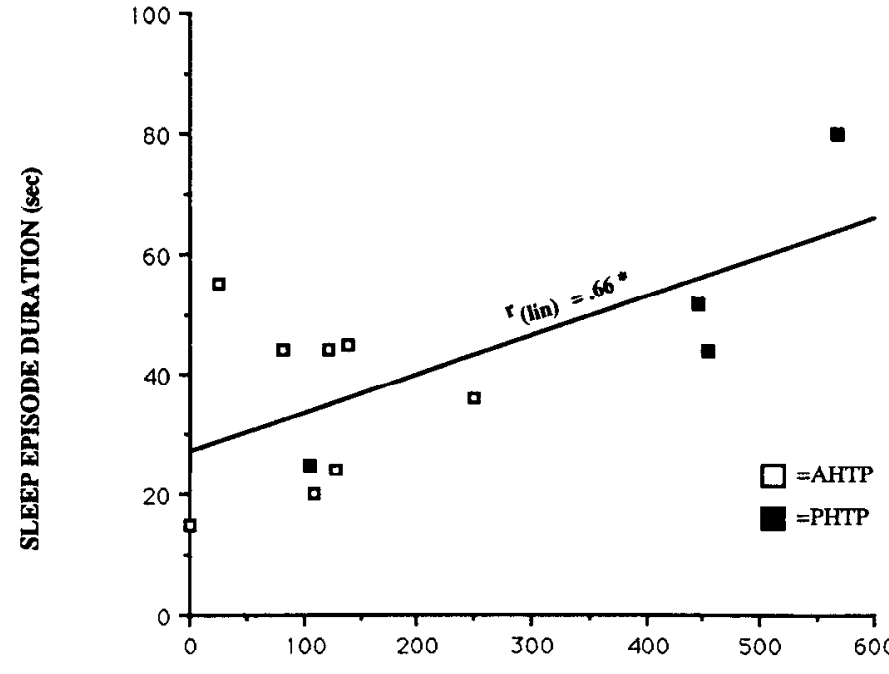

ChAT CELLS IN HABENULAR TRANSPLANTS

Figure 5. Correlation of ChAT cell number in habenula transplants with duration of sleep episodes. The number of ChAT-positive cells in transplants of habenular origin correlates with duration of the animals' sleep episodes as measured behaviorally in the flower pot test. The significant linear correlation is dependent on the perinatal host animals (PHTP); the adult host animals (AHTP) have relatively small numbers of ChAT cells in their transplants (see Sleep behaviors, above). 
statistical correlation for all animals with habenular transplants is likely the result of that wider range in the perinatal hosts.

\section{Physiological measures}

At the start of behavioral testing the average weight for each group of animals ranged from $303( \pm 21) \mathrm{gm}$ in normals to 354 $( \pm 30) \mathrm{gm}$ in animals with adult lesions and thalamus transplants, differences that were not statistically significant. By the end of the $4 \mathrm{~d}$ assay, each operated group had a net weight loss while the normal group had a net weight gain, but there were no statistically significant differences between any pair of groups in either the direction of their weight change or its absolute magnitude. Similarly, at the beginning of the assay period, body temperatures ranged only slightly across all animals, from $35.0^{\circ} \mathrm{C}$ to $38.1^{\circ} \mathrm{C}$, and had not changed significantly by the end of the test period for any group.

In the other two measures, number of grooming episodes and number of fecal boli, the only suggestion of a between-group difference was in the number of fecal boli for the perinatal lesiononly group: $9.4( \pm 1.6)$ over the last $3 \mathrm{hr}$ period on the flower pot, compared to $5.0( \pm 1.6)$ for normals, a difference that just misses statistical significance at $p<0.06$.

\section{Discussion}

The principal findings of this study are that (1) disruption of the habenulo-interpeduncular pathway alters components of both REM and non-REM stages of sleep, (2) transplants in these lesioned animals that reestablish peptidergic innervation of the IPN restore the REM component to an extent that is highly predictable from the number of SP-positive cells in the transplant, and (3) transplants that reestablish a cholinergic innervation of the IPN restore the non-REM component to an extent that is predictable from the number of cholinergic cells in the transplant only when the cells are derived from a normal IPN afferent.

\section{Functions of the habenulo-interpeduncular system}

The habenula and IPN have been classically thought of as part of the limbic system outflow into the brainstem (Nauta, 1958), with more recent anatomical evidence suggesting ascending influences as well (Vertes and Fass, 1988). Standard ablationbehavior and stimulation-behavior studies of the two nuclei and the fiber bundle connecting them, the FR, have not led to a consensus on the functions of this system (reviewed in Sutherland, 1982). The most consistent behavioral finding after lesions has been a deficit in active avoidance learning (Wilson et al., 1972; Wirtshafter, 1981; Thornton and Bradbury, 1989), and recent behavioral as well as pharmacological stimulation studies have emphasized the role of stress in habenular-interpeduncular functions (Thornton and Bradbury, 1989), a role that appears to involve the peptidergic component of the system (Lisoprawski et al., 1981; Nishikawa et al., 1986).

Based on the connections of the IPN and its pattern of metabolic activity, Shibata et al. (1986) suggested it may have some role in sleep regulation. Results of the present study provide the first direct support for this idea. Deafferenting the IPN of its medial habenula input by bilateral FR lesions significantly reduces both the frequency and duration of sleep episodes, and nearly eliminates one particular component of REM-stage sleep, muscle atonia, during the acute test period. The measures of these disruptions in sleep cycle integrity are behavioral rather than electrophysiological, but the method used is known to correlate with EEG assessment of sleep stages (see introductory remarks).

In this platform or "flower pot" method, the most straightforward behavioral result of placing the animal on a smalldiameter inverted flower pot in a water tank during its normal sleep period is loss of postural tone as the animal enters REMstage sleep (Cohen and Dement, 1964; Kushida et al., 1989), a flaccidity that leads to the animal contacting the water, causing it to awaken. Chronically, this procedure results in REM deprivation. In the present study, the animals were only briefly placed on the flower pot. We interpret the frequency of water contact during this acute period as a measure of either the frequency of REM-induced atonia, or the degree of its completeness (i.e., whether the atonia is severe enough to lead to the rat tilting into the water). Under either interpretation, the FR lesion results in a disruption in this REM-associated sleep behavior.

We do not interpret the near-complete absence of water contacts in the adult lesion-only group as evidence that the FR lesion results in chronic REM deprivation. These animals exhibit none of the classic symptoms of chronically REM-deprived animals-yellowish-brown fur, plantar and tail lesions, weight loss, and increased mortality (Kushida et al., 1989). In addition, there were no significant effects on several physiological measures of stress associated with REM deprivation. Rather, the REM disruption appears selective for the muscle atonia component. A selective loss of muscle atonia during REM also results from lesions in the anterodorsal pons (Jouvet and Delorme, 1965; Sastre et al., 1981).

FR lesions also reduce the duration of the animals' sleep episodes by half. This decrease cannot solely be the result of REM sleep loss, since in rats the duration of REM-stage sleep, as defined by EEG pattern, has been variously reported as comprising between $10 \%$ and $20 \%$ of total sleep time (Van Twyver, 1969; Kushida et al., 1989; Rampin et al., 1991; Trampus et al., 1991). Therefore, even if the FR lesions did completely eliminate all REM-stage components, most of the reduction in total sleep time must still reflect a reduction in non-REM sleep, most likely in the high-amplitude synchronized components (Gilliland et al., 1989). Therefore, both REM and non-REM aspects of the pattern of sleep behavior are disrupted by FR lesions that deafferent the IPN.

\section{Transplant-mediated behavioral sparing}

$S P$ neurons and REM-sleep behavior. The severe disruption in REM atonia following FR lesions is completely prevented by transplants of embryonic habenula cells placed near the denervated IPN (Fig. 2). These same transplants mediate enhanced SP staining in specific subnuclei of the IPN (see companion article). Both of these transplant effects are specific, in that transplants of thalamus cells, which at the time of implanting contain the same number of viable cells as the habenula transplants, do not have an overall effect on water contact frequency and do not restore SP staining in the IPN. The ineffectiveness of thalamus transplants is attributable to their containing reduced numbers of peptidergic cells, compared to the number in habenular transplants (Table 2). The thalamus normally contains few if any peptidergic cells when mature (Jonakait et al., 1991), so this result is not surprising.

The recovery of REM atonia is strongly dependent on the number of SP-positive cells in the transplants, suggesting this aspect of REM is peptidergically mediated (Fig. 4). Even the 
few peptidergic cells in the thalamus transplants apparently contribute to this behavior, because the correlation between water contact frequency and SP cell number is reduced in magnitude if data from the thalamus transplant animals is not included. This result suggests that even small numbers of transplant cells of a particular phenotype may increase the probability of a specific behavior.

The mechanism of the transplant SP cells' effect on this behavior may be via direct projections to the IPN, with the probability of the density of the projection closely related to the specific number of those cells. Alternatively, the SP cells may secrete a diffusible factor, perhaps SP itself, with the total quantity of the factor closely related to the number of SP cells in the transplant and to its net influence on host cell activity. There is evidence from other studies that both mechanisms may lcad to significant quantitative correlations with behavioral measures. The area of retinal transplant innervation of the deafferented host olivary pretectal nucleus is correlated $\left(r_{\text {lin }}=0.84\right)$ with the intensity of the pupillary eye reflex (Klassen and Lund, 1990 ); the number of dopaminergic cells in intrastriatal transplants is correlated $\left(r_{\operatorname{lin}}=0.56\right)$ with a reduction in 6-hydroxydopamine lesion-caused rotational asymmetry (Brundin et al., 1988).

Interestingly, both these quantitative correlations are best described by a logarithmic relationship (a sigmoidal curve), which is also the result here. In three very different systems, then, the quantitative relationship between transplants and functional recovery follows the same course. As the transplants' effect on the host increases, the size of the increments in behavioral recovery begins to decrease. This strongly implies host regulation of the transplants' functional consequences.

The association between REM atonia recovery and SP staining in the IPN also suggests a normal involvement of the IPN in this aspect of the sleep cycle. The most consistent and obvious anatomical effect of the habenula transplants is an increase in SP staining intensity in the ventral portion of the rostral subnucleus of the IPN (Eckenrode et al., 1992). The SP cells located there project to the caudal portion of the dorsal tegmentum (Huitinga et al., 1985; Groenewegen at al., 1986), which in turn sends cholinergic projections (Quattrochi et al., 1989) to the "REM sleep induction zone" in the dorsomedial pons (Yamamoto et al., 1990). By this pathway, the IPN may exert a kind of fine-tuning control on the atonia component of REM sleep.

Cholinergic neurons and non-REM-sleep behavior. The duration of sleep episodes in FR-lesioned animals is half that in normals, with most of this reduction occurring in the non-REM sleep stage (see above). Transplants that mediate ChAT reinnervation in the IPN (thalamus transplants in adults, habenula transplants in perinates) restore normal sleep times (Fig. 3). In contrast, lesioned animals with transplants that do not mediate ChAT innervation in the IPN (habenular transplants in adult hosts) have reduced sleep time. Thus, restoration of ChAT staining in the IPN of FR-lesioned hosts is associated with recovery of non-REM sleep behavior.

The presence of large, well-differentiated cholinergic neurons in thalamus transplants is surprising, since the mature thalamus does not normally contain cholinergic neurons (Jones, 1985). ChAT-positive cells in our thalamus transplants are not likely a result of contamination of the donor tissue by, for example, striatal or basal forebrain cholinergic neurons, because our dissection avoids the forebrain. Rather, these thalamus cells may have retained a transient immature phenotype when placed in this ectopic location (see Eckenrode et al., 1992, for discussion).

The failure of habenula transplants in adult lesion hosts to improve sleep duration or to mediate any cholinergic reinnervation in the IPN may be attributable to a significantly reduced number of cholinergic cells in the habenula transplants of adult hosts, compared to the number in both thalamus transplants in adult hosts and habenular transplants in perinatal hosts (Table 2). This reduction does not reflect a general impairment in survivability in adult versus perinatal hosts (Hallas et al., 1980) because the number of cholinergic cells in adult thalamus transplants is nearly identical to that in perinatal habenula transplants. Rather, the diminished cholinergic cell survival in adult hosts may result from constraints on synapse formation by habenular cholinergic afferents that normally begin in the late perinatal period, constraints not effective on the anomalous thalamic cholinergic cells (discussed in Eckenrode et al., 1992).

While the two transplant groups showing ChAT reinnervation of the IPN have improved sleep duration times, they have very different relationships between the number of cholinergic cells in their transplants and recovery of sleep duration. The number of cholinergic cells of habenular origin is a significant predictor of sleep duration (Fig. 5), while number of cholinergic cells of thalamic origin has only a random relationship with sleep duration.

The number of animals in these two groups is small, so conclusions are limited. Nonetheless, one clear possibility is that habenular cholinergic neurons mediate their effect on sleep duration directly through one pathway (perhaps involving normal cholinergic targets in the IPN) while thalamic neurons (possibly not the cholinergic population) affect another pathway that also contributes to recovery of sleep duration. These alternatives may be resolved by "preculturing" the transplants to manipulate in vitro the proportions of various cell types that when transplanted integrate with host functions by different means.

\section{References}

Abercrombie M (1946) Estimation of nuclear population from microtome sections. Anat Rec 94:239-247.

Artymyshyn R, Murray M (1985) Substance P in the interpeduncular nucleus of the rat: normal distribution and effects of deafferentation. J Comp Neurol 231:78-90.

Barr GA, Eckenrode TC, Murray M (1987) Normal development and the effects of early deafferentation in choline acetyltransferase, substance $\mathrm{P}$ and serotonin like immunoreactivity in the interpeduncular nucleus. Brain Res 418:301-313.

Bergmann BM, Kushida CA, Everson CA, Gilliland MA, Obermeyer W, Rechtschaffen A (1989) Sleep deprivation in the rat: II. Methodology. Sleep 12:5-12.

Bjorklund A, Dunnett SB, Stenevi U, Lewis ME, Iversen SD (1980) Reinnervation of the denervated striatum by substantia nigra transplants: functional consequences as revealed by pharmacological and sensorimotor testing. Brain Res 199:307-333.

Brundin P, Isacson O, Bjorklund A (1985) Monitoring of cell viability in suspensions of embryonic CNS tissue and its use as a criterion for intracerebral graft survival. Brain Res 331:251-259.

Brundin P, Barbin G, Strecker RE, Isacson O, Prochiante A, Bjorklund A (1988) Survival and function of dissociated rat dopamine neurons grafted at different developmental stages or after being cultured in vitro. Dev Brain Res 39:233-243.

Cohen HB, Dement WC (1964) Sleep: changes in threshold to electroconvulsive shock in rats after deprivation of "paradoxical" phase. Science 150:1318-1319.

Contestabile A, Villani L, Fasolo A, Franzoni MF, Gribaudo L, Oktedalen O, Fonnum F (1987) Topography of cholinergic and substance $P$ pathways in the habenulo-interpeduncular system of the rat. Neuroscience $21: 253-270$. 
Dunnett SB, Low WC, Iversen SD, Stenevi L, Bjorklund A (1982) Septal transplants restore maze learning in rats with fimbria-fornix lesions. Brain Res 251:335-348.

Dunnett SB, Toniolo G, Finc A, Ryan CN, Bjorklund $\Lambda$, Iversen SD (1985) Transplantation of embryonic ventral forebrain neurons to the neocortex of rats with lesions of the nucleus basalis magnocellularis. II. Sensorimotor and learning impairments. Neuroscience 16: 787-797.

Dunnett SB, Ryan CN, Levin PD, Reynolds M, Bunch SD (1987) Functional consequences of embryonic neocortex transplanted to rats with prefrontal cortex lesions. Behav Neurosci 101:489-503.

Dunnett SB, Martel FL, Rogers DC, Finger S (1989) Factors affecting septal graft amelioration of differential reinforcement of low rates (DRL) and activity deficits after fimbria-fornix lesions. Res Neurol Neurosci 1:83-92.

Eagleson KL, Haun F, Cunningham TJ (1990) Different populations of dorsal lateral geniculate nucleus neurons have concentration-specific requirements for a cortically derived neuron survival factor. Exp Neurol 110:284-290.

Eckenrode TC, Barr G, Battisti W, Murray M (1987) Acetylcholine in the interpeduncular nucleus of the rat: normal distribution and effects of deafferentation. Brain Res 418:273-286.

Eckenrode TC, Murray M, Haun F (1992) Habenula and thalamus cell transplants mediate different specific patterns of innervation in the interpeduncular nucleus. J Neurosci 12:3274-3284.

Freed WI, Perlow MI, Karoum F, Seiger A, Olson L, Hoffer BJ, Wyatt RJ (1980) Restoration of dopaminergic function by grafting of fetal rat substantia nigra to the caudate nucleus: long-term behavioral, biochemical, and histochemical studies. Ann Neurol 8:510-519.

Gage FH, Bjorklund A (1986) Enhanced graft survival in the hippocampus following selective denervation. Neuroscience 17:89-98.

Gilliland MA, Bergmann BM, Rechtschaffen A (1989) Sleep deprivation in the rat: VIII. High EEG amplitude sleep deprivation. Sleep 12:53-59.

Groenewegen HJ, Ahlenius S, Haber SN, Kowall NW, Nauta WJH (1986) Cytoarchitecture, fiber connections, and some histochemical aspects of the interpeduncular nucleus in the rat. J Comp Neurol 249: 65-102.

Hallas BH, Das GD, Das KG (1980) Transplantation of brain tissue in the brain of rat. II. Growth characteristics of neocortical transplants in hosts of different ages. Am J Anat 158:147-159.

Haun F, Cunningham TJ (1987) Specific neurotrophic interactions between cortical and subcortical visual structures in developing rat: in vivo studies. J Comp Neurol 256:561-569.

Haun F, Cunningham TJ, Rothblat LA (1989) Neurotrophic and behavioral effects of occipital cortex transplants in newborn rats. Vis Neurosci 2:189-198.

Herkenham M (1981) Anesthetics and the habenulo-interpeduncular system: selective sparing of metabolic activity. Brain Res 210:461466.

Huitinga I, van Dijk CA, Groenewegen HJ (1985) Substance P and enkephalin containing projections from the interpeduncular nucleus to the dorsal tegmental region in the rat. Neurosci Lett 62:311-316.

Jonakait GM, Ni L, Walker PD, Hart RP (1991) Development of substance $\mathrm{P}$ (SP)-containing cells in the central nervous system: consequences of neurotransmitter co-localization. Prog Neurobiol 36:121.

Jones EG (1985) The thalamus. New York: Plenum.

Jouvet M, Delorme F (1965) Locus coeruleus et sommeil paradoxal. CR Soc Biol (Paris) 159:895-899.

Kennedy C, Gillin JC, Mendelson W, Suda S, Miyaoka M, Ito M, Nakamura RK, Storch FI, Pettigrew K, Mishkin M, SokoloffL (1982) Local cerebral glucose utilization in non-rapid eye movement sleep. Nature 297:325-327.

Kirk RE (1968) Experimental design: procedures for the behavioral sciences, pp 494-497. Belmont, CA: Brooks-Cole.

Klassen H, Lund RD (1990) Parameters of retinal graft-mediated responses are related to underlying target innervation. Brain Res 533: 181-191.

Kunkel-Bagden E, Bregman BS (1990) Spinal cord transplants enhance the recovery of locomotor function after spinal cord injury at birth. Exp Brain Res 81:25-34.

Kushida CA, Bergmann BM, Rechtschaffen A (1989) Sleep deprivation in the rat: IV. Paradoxical sleep deprivation. Sleep 12:22-30.

Lisoprawski A, Blanc G, Glowinski J (1981) Activation by stress of the habenulo-interpeduncular substance $\mathrm{P}$ neurons in the rat. Neurosci Lett 25:47-51.

Lydic R, Baghoyan HA, Hibbard L, Bonyak EV, DeJoseph MR, Hawkins RA (1991) Regional brain glucose metabolism is altered during rapid eye movement sleep in the cat: a preliminary study. J Comp Neurol 304:517-529.

McGrath MJ, Cohen DB (1978) REM sleep facilitation of adaptive waking behavior: a review of the literature. Psychol Bull 85:24-57.

McQueen JK, Martin MJ, Harmon AJ (1984) Local changes in cerebral 2-deoxyglucose uptake during alphaxalone anesthesia with special references to the habenulo-interpeduncular system. Brain Res 300: 19-26.

Mendelson WB, Guthrie RD, Frederick G, Wyatt RJ (1974) The flower pot technique of rapid eye movement (REM) sleep deprivation. Pharmacol Biochem Behav 2:553-556.

Morden B, Mitchell G, Dement W (1967) Selective REM sleep deprivation and compensation phenomena in the rat. Brain Res 5:339349.

Motohashi N, MacKenzie ET, Scatton B (1986) Functional mapping of the effects of lesions of the habenular nuclei and their afferents in the rat. Brain Res 397:265-278.

Nauta WJH (1958) Hippocampal projections and related neural pathways to the midbrain in the cat. Brain 81:319-341.

Nilsson OG, Shapiro ML, Gage FH, Olton DS, Bjorklund A (1987) Spatial learning and memory following fimbria-fornix transection and grafting of fetal septal neurons to the hippocampus. Exp Brain Res 67:195-215.

Nishikawa T, Fage D, Scatton B (1986) Evidence for, and nature of, the tonic inhibitory influence of habenulo-interpeduncular pathways upon cerebral dopaminergic transmission in the rat. Brain Res 373: 324-336.

Quattrochi JJ, Mamelak AN, Madison RD, Macklis JD, Hobson JA (1989) Mapping neuronal inputs to REM sleep induction sites with carbachol-fluorescent microspheres. Science 245:984-986.

Ralph MR, Foster RG, Davis FC, Menaker M (1990) Transplanted suprachiasmatic nucleus determines circadian period. Science 247 975-978.

Rampin C, Cespuglio R, Chastrette N, Jouvet M (1991) Immobilization stress induces a paradoxical sleep rebound in rat. Neurosci Lett 126:113-118.

Rideout, BE (1979) Non-REM sleep as a source of learning deficits induced by REM sleep deprivation. Physiol Behav 22:1043-1047.

Sastre JP, Sakai K, Jouvet M (1981) Are the gigantocellular tegmental field neurons responsible for paradoxical sleep? Brain Res 229:147161.

Shibata H, Suzuki T (1984) Efferent projections of the interpeduncular complex in the rat, with special reference to its subnuclei: a retrograde horseradish peroxidase study. Brain Res 296:345-349.

Shibata H, Suzuki T, Matsushita M (1986) Afferent projections to the interpeduncular nucleus in the rat, as studied by retrograde and anterograde transport of wheat germ agglutinin conjugated to horseradish peroxidase. J Comp Neurol 248:272-284.

Smolen AJ, Wright LL, Cunningham TJ (1983) Neuron numbers in the superior cervical ganglion of the rat: a critical comparison of methods for cell counting. J Neurocytol 12:739-750.

Steriade M, McCarley RW (1990) Brainstem control of wakefulness and sleep. New York: Plenum.

Sutherland, RJ (1982) The dorsal diencephalic conduction system: a review of the anatomy and functions of the habenular complex. Neurosci Biobehav Rev 6:1-13.

Swisher, JE (1962) Manifestations of "activated" sleep in the rat. Science 138:1110.

Thornton EW, Bradbury GE (1989) Effort and stress influence the effect of lesion of the habenula complex on one-way active avoidance learning. Physiol Behav 45:929-935.

Trampus M, Ferri N, Monopoli A, Ongini E (1991) The dopamine $D_{1}$ receptor is involved in the regulation of REM sleep in the rat. Eur J Pharmacol 194:189-194.

Van Twyver H (1969) Sleep patterns of five rodent species. Physiol Behav 4:901-905.

Vcrtes RP (1990) Brainstem mechanisms of slow-wave and REM sleep. In: Brainstem mechanisms of behavior (Klemm WR, Vertes RP, eds), pp 535-583. New York: Wiley.

Vertes RP, Fass B (1988) Projections between the interpeduncular nucleus and basal forebrain in the rat as demonstrated by the an- 
terograde and retrograde transport of WGA-HRP. Exp Brain Res 73: 23-31.

Wilson RJ, Mitchell JC, Van Hoesen GW (1972) Epithalamic and ventral tegmental contributions to avoidance behavior in rats. J Comp Physiol Psychol 78:442-449.

Wirtshafter D (1981) The role of interpeduncular connections with the tegmentum in avoidance learning. Physiol Behav 26:985-989.
Yamamoto K, Mamelak AN, Quattrochi JJ, Hobson JA (1990) A cholinoceptive desynchronized sleep induction zone in the anterodorsal pontine tegmentum: locus of the sensitive region. Neuroscience 39:279-293. 